\title{
Abstracts
}

\section{ANNUAL MEETING}

\section{European Society for Paediatric Research}

\author{
Athens, Greece June 1-4, 1980
}

\section{COUNCIL OF THE EUROPEAN SOCIETY FOR PEDIATRIC RESEARCH}

D. Nicolopoulos, Athens, President

N. Herschkowitz, Bern, President Elect

L. Corbeel, Leuvan, Past President

J. Gentz, Stockholm, Secretary

R. Gitzelmann, Zurich, Treasurer

J.D. Baum, Oxford

J.F. Desjeux, Paris

M.A. Cser, Budapest

$H$. Versmold, Munich

DEFECTIVE OPSONIZATION IN RECURRENT INFECTIONS G. Van den Berghe, K. De Boeck* ${ }^{*}$ L. Corbeel and R. EEckels s*

Dept. of Paediatrics, University of Leuven, Belgium. Deficient opsonization of yeasts, assessed by a microscopic method, has been reported as a trequent occurrence in children with recurrent infections (Soothill \& Harvey, Arch. Dis. Childh. 51: 91, 1976) and in atopic patients (Turner et al.Clin. exp. Immunol. 34. 253,1978 ). We have studied opsonization spectrophotometricaliy by the stimulation, induced by serum, of the reduction of nitrobluetetrazolium which accompanies the phagocytosis of zymosan by PMN leucocytes. In 44 normal adults, half-maximal stimulation (S 0.5 ) was observed with a serum concentration of $3.1 \%+0.6$ (mean + st. dev.) Opsonization was considered deficient when ${ }^{-} S 0.5$ was $i \bar{n} c r e a-$ sed above $4.3 \%$ ( +2 st.dev.). In accordance with Soothill et al., defective opsonization was occasionally found in healthy adults $(3 / 47)$. Opsonization was studied in 91 children divided in 4 groups. In 22 children with various non-infectious diseases, including 6 with eczema, opsonization was normal. Deficient opsonization was found in 4 (14.3\%,n.s.) out of 28 children hospitalized for a sirigle acute infection, in $9\left(50 \%, X^{2}=13.7, P<0.001\right)$ out of 18 children with a history of 3 or more severe infections (pneumonia, meningitis. sepsis) and in 2 ( $8.7 \%, n . s$.) out af 23 children with frequent more benign infections (otitis, bronchitis). These results confirm the association of defective opsonization with an increased susceptibility to severe recurrent infections. and $K$. Betke.

Kinderkinik der Universitat Munchen, LindwurmstraBe 4, D-8000 Munchen 2, west Germany.

One of the disturbing problems of pediatric practice is that of the child with persistent or recurring respiratory tract infections. Only in about 25 of these children humoral immunodefects can be detected. We investigated two parameters of cellular immunocompetence: (1) antigen-or mitogen-induced proliferation and (2) lymphotoxin production (Methods: Cellular Immunol. 46: 35, 1979) of peripheral blood lymphocytes from children with recurrent bronchopulmonary infections. Out of 30 patients with normal or even elevated serum immunoglobulins, eight patients showed a significantly reduced (less than $10 \%$ of normal values) lymphotoxin production. Since defects in lymphotoxin production have been found to be correlated with cellular immunodeficiencies (Mschr. Kinderheilk. 123: 402, 1975) we conclude from our data that cellular immunodefects have to be considered as another cause of recurrent respiratory tract infections. (This work was supported by the "Stiftung Volkswagenwerk" 3 and W. MULLER Medizinische Hochschule Hannover, 3 Hannover 61 , and Institut fur virologie und Immunbiologie der Universität Wurzbu=g, 87 Würm burg, W. Germany. Deficiency of 5 ' nucleotidase ( 5 ' $\mathrm{i}$ ) in humoral and cellular immunedefects (I.D.)

Iymphocyte $5^{\prime} \mathrm{N}$ was assessed in x-linked agammaglobulinemia $(x-L A, n=3)$, ataxia-telangiectasia $(n=3)$, Viscott-Aldrich-syndrom $(n=1)$, combined immunodeficiency $(n=1)$, and dysgammaglobulinemia with autoimmune hemolytic anemia ( $n=1$, HLA-identical brother of 1 patient with $X-I A$ ). Controls were 14 normal children (mean age $7.3 \pm 4$ yrs.j. Lymphocytes were separated over a Ficollgradient, concentrated in KCl-Tris-buffer and stored at $-85 \mathrm{C}$. Nithin 3 weeks the cells were thawn up and sonified. 5 'N was measured by a new spectrophotometric assay. Results were expressed as mU (IU=disappearance of 1 mol of substrate per minute at $30^{\circ} \mathrm{C}$ ). Range of 5 N activities in the patient group was $0.68-9.55, \mathrm{U}$, mean $3.56 \mathrm{Ut2} .9 \mathrm{~S}$. D. Range of controls was $12-56.5 \mathrm{U}$, mean 34.36 Ut15.5. Except for patients with $x \rightarrow L A$, impairment of both cellular and humoral immunity was found in all patients. The finding of 5 'N deficiency in a variety of I.D. and the fallure to correlate this defect with a specific immunedysfunction, suggests that $5^{\prime} \mathrm{N}$ is a marker of Iymphocyte differentiation rather than the genetic defect underlying a specific disease.

\footnotetext{
4 B.BETEND, J.L. TOURAINE* M. HERMIER, R. FFANCOIS Department of pediatrics and Unité INSERM 80, Hopiial Edouard Herriot and UeR Alexis Carrel, Lyon, France. Reconstitution in severe combined immunodeficiency desease (SCID) by fetal tissues transplantations.

When 3 weeks and $5 \div$ months old, a boy with an autosomal form of SCID received 2 successive transplantations of mixed hepatic and thymic cells ; each transplant was obtained from anique fetus gestational ages of the 2 donors were 13 and 10 weeks respectively. The infant was maintained in strict isolation from the 3 rd day of life until 18 months. Slow immunololation from the 3 rd day of $T$ cells functions became normal on day 330 after the ind transplan' $\mathrm{T}$ cells functions became normal on day 330 after the Ind transplantation and a marked improvment of the humoral immunity without comlete normalization was observed on day 400 . No graft-versus-host reaction appeared. Persisting chimaerism was documented : $T$ cells derived from the donor, B cells were of host origin and there was evidence for a double erythrocytic population. Af: er isolator, the child developped two severe bacterial infections pneumonitis and a Haemophilus influenzae meningitis - which reveapneumonitis and a Haemophilus influenzae meningitis - which revealed a chemotactic and a phagocytic defect of polymorphonuclear yranulocytes (PMN) and were successfully treated. He now enjoys a normal life, more than 3 years after the 2nd transplantation. Experience gained from this case indicates : 1) fetal tissues may provide a useful treatment for patients with Scid who lack bone-marrow his tocompatible donor, 2) despite complete HLA mismatch between $T$ and tocompatible donor, 2) despite complete HLA mismatch between $T$ and B cells the phenomenon of "alloyeneic restriction" may not be as absolute in man as in mice, 3) the PMN defect(s) may indicate some heterogeneity in this immunodeficiency disease.
} 